\title{
LA ENCOMIENDA DE SOR ÁGUEDA DEL PADRE ETERNO Y SOR FELICIANA DE SAN ANTONIO, EN CHIAPAS*
}

\author{
Luis Millet Cámara \\ Depto. de Salvamento Arqueológico \\ del I. N. A. H.
}

\section{Introducción}

Al depender la provincia de Chiapas de la Real Audiencia de Los Confines que tuvo su sede en la ciudad de Guatemala durante la mayor parte de la época Colonial, y como siendo el presidente de esa Audiencia la persona con facultades para poder dar encomiendas en su jurisdicción de acuerdo con la autorización real, el desarrollo de la encomienda fue quedando enmarcado en las condiciones prevalecientes, tanto en el reino de Guatemala como en las que existían en otras regiones del imperio español. Sin embargo, esta institución presentó algunas características propias en cada una de las partes donde funcionó; características de interés e importancia para comprender el desarrollo y configuración de las condiciones sociales del momento presente.

Pasados los primeros años de la conquista y cuando la encomienda experimenta las limitaciones impuestas por la Corona a los intereses de los conquistadores, el desarrollo que siguió en Chiapas y en el resto de la América española la llevaron hasta su total desaparición hacia el siglo xvmr. Encontramos a la encomienda en una situación de crisis muy pronunciada desde los últimos años del siglo xvII, debido principalmente a las cargas económicas que continuamente le señalaba el gobierno español tratando de reducir el enorme déficit financiero de España, circunstancia que facilitó la eliminación final de las encomiendas por la real cédula dada en Balsain el 27 de septiembre de 1721 , en la que el rey ordenaba que lo obtenido de las encomiendas se integrara al ramo de tributos de la Real Hacienda.

* Revisión a cargo de Mario Humberto Ruz.

Estudios de Cultura Maya. Vol. XIII, 1981

Instituto de Investigaciones Filológicas/

Centro de Estudios Mayas, UNAM

http://www.iifilologicas.unam.mx/estculmaya/ 
La reacción de los encomenderos en América ante la desaparición de las encomiendas fue débil, casi nula. En gran parte esta actitud se debió a que la institución se fue volviendo cada vez menos productiva, dadas las pesadas cargas fiscales. En Chiapas, esta pasividad se vio aumentada debido a que las principales encomiendas y las que mayores beneficios daban, estaban en su mayoría en manos de personas que residían en España, por lo general, personajes allegados a la corte.

El estudio de la encomienda que desde finales del siglo xvi poseían las religiosas Sor Águeda del Padre Eterno y Sor Feliciana de San Antonio, del convento de las Carmelitas, llamado también de la Baronesa, en Madrid, nos ha proporcionado abundante información, pues era una de las encomiendas más antiguas de la región en manos de personas residentes en España. La larga secuencia de datos se inicia en 1620, cuando ambas religiosas entran en posesión de lo que fue una de las más ricas encomiendas que hubiera en tierras chiapanecas. Gracias a las numerosas excepciones que hiciera el rey para que las religiosas pudieran gozar de dicha merced, se originó una copiosa documentación que ilustra con bastante detalle el funcionamiento y la problemática interna de la posesión y administración de una en. comienda.

La larga duración de esta encomienda, que estuvo en posesión de cinco individuos de la misma familia desde principios del siglo xvI hasta pasada la primera mitad del siglo xvir, no es un caso típico en Chiapas, donde por lo general las encomiendas se ajustaron a la ley de sucesión que señalaba como el periodo de disfrute de las mismas el de dos vidas; la del que obtenía el beneficio y la de un heredero. Asimismo, presenta esta encomienda otros aspectos poco frecuentes en las que poseían las personas residentes en el Reino de Guatemala, pues sus primeros poseedores fueron gente con altos cargos en la administración de las Indias o allegados a la corte. Pero por estas circunstancias tan especiales, no deja de tener interés el caso que a continuación se estudia, que esperamos ayudará al conocimiento de la encomienda en Chiapas.

\section{Obtención y sucesión de la encomienda}

Por real cédula de Felipe III, de fecha del 5 de diciembre de 1620 se le comunica a Don Antonio Peraza de Ayala, Conde de la Gomera, presidente de la Audiencia con sede en Guatemala, que se le había hecho merced a Don Gregorio González de Cuenca y Contreras, fiscal 
del rey en la Casa de la Contratación de las Indias, de una encomienda con valor de mil ducados sobre los tributos vacos de ese reino.

El Conde de la Gomera situó inicialmente dicha encomienda en los pueblos de Soyatitlán, en los Llanos, provincia de Chiapas; en las parcialidades de Amatán y Tapizala, comprendidas en el pueblo de Tecpatán; en la parcialidad de Tutuapa del pueblo de Ixtacomitán; en la de San Jacinto, comprendida en el pueblo de Chapultenango y asimismo el pueblo de Pantepeque, todos estos últimos situados en la provincia de los Zoques, también en Chiapas. Cuando se hizo la nueva cuenta de los tributarios de los pueblos, a solicitud de sus habitantes, se encontró que los tributos no ajustaban los mil ducados, a causa de la disminución habida en la población desde la última tasación efectuada por Don Matías Solís de Ulloa y Quiñones, oidor de la Audiencia. En vista de lo anterior, el Conde de la Gomera le dio en encomienda el pueblo de Langue situado en la provincia de San Salvador, el 17 de marzo de 1624, con el cual se completaba la cantidad estipulada, pero la solución no fue aceptada por Don Gregorio González, ni por su apoderado, avecindado en la ciudad de Guatemala:

y se ha hecho relación a su señoría que no aceptarla es por tener como tiene la encomienda principal en la dicha provincia de Chiapa como se ha referido, que está distante de la de San Salvador ciento y veinte leguas y ser distantes provincias de que se le siguen muchos inconvenientes y gastos en la cobranza, y el principal es ser forzoso poner dos escuderos como tal encomendero, en cada provincia el suyo. . . ${ }^{1}$

Para evitar los inconvenientes anteriores, y habiendo quedado vaco el pueblo de San Andrés Nicapa, situado en los Zoques, por muerte de su encomendera Doña María Agüero, viuda del capitán Miguel Rodríguez de Elpadrón; se cambió el pueblo de Langue por el recientemente vaco con objeto de tener a todos los pueblos dentro de la provincia de Chiapas. Así, en 1625 se le expidió título de encomendero a Don Gregorio González, compartiendo el último pueblo mencionado con Don Melchor de Solórzano, vecino de Ciudad Real. ${ }^{2}$ A partir de esta fecha el producto total de la encomienda comprendería los tributos de estos pueblos, permaneciendo así hasta su extinción en el año de 1757, en que murió Sor Feliciana, la última encomendera.

A la muerte de Don Gregorio González hereda la encomienda Don Diego González de Cuenca y Contreras, quien estaba casado con Doña

1 AGDCA, A3.16 leg. 2803 exp. 40524.

2 Ibid.

Estudios de Cultura Maya. Vol. XIII, 1981

Instituto de Investigaciones Filológicas/

Centro de Estudios Mayas, UNAM

http://www.iifilologicas.unam.mx/estculmaya/ 
Águeda de Castro. Don Diego era gentilhombre de boca del rey y gozó de la encomienda hasta su muerte que debió de ocurrir cerca del año de 1686, pues en esa fecha, por cédula de Carlos II pasó a disfrutar de ella, en tercera vida, Don Gregorio, hijo de los anteriores.

Pocos debieron de ser los recursos económicos que poseía la familia, ya que deseando Don Gregorio entrar al convento de los monjes Capuchinos se abstenía de hacerlo, temiendo perder el derecho a seguir disfrutando de su encomienda (ya que de acuerdo a lo que estaba señalado en la Recopilación de Leyes de Indias, los religiosos no podían poseer encomiendas). ${ }^{3}$ Ante la necesidad de sostener a su madre y a una hermana soltera de nombre Feliciana, Don Gregorio solicita al rey que traspase a ellas el disfrute de la encomienda, a lo cual accedió el monarca comunicándole su decisión a Jacinto Barrios, presidente de la Audiencia, en una real cédula fechada el 31 de enero de 1690, donde se autoriza que Doña Águeda y Doña Feliciana entren a gozar de la encomienda, solamente por una vida, lo que permitió a Don Gregorio retirarse a la vida monástica. Poco tiempo después las nuevas encomenderas deciden entrar a un convento y piden al rey que se les permita seguir gozando de la merced, ya que con su producto esperan pagar sus deudas y obtener su ingreso. Haciendo una excepción a las leyes el rey se las concede, enviando su decisión a Guatemala en real cédula del 2 de diciembre de 1691. Ingresan entonces al convento de la Natividad y el Señor San José de las Carmelitas Descalzas, también llamado La Baronesa, en la villa de Madrid, tomando los nombres de Sor Águeda del Padre Eterno y Sor Feliciana de San Antonio. ${ }^{4}$

Bajo las nuevas poseedoras la encomienda conoce una etapa de frecuentes problemas administrativos, ya que al poco tiempo de entrar al convento, celebran un contrato de arrendamiento de la misma con Don Antonio de Villela y Arce, Conde de Lenses, fechado en Madrid el 10 de febrero de 1693. Tal contrato siguió vigente hasta el 16 de octubre de 1704, fecha en que murió el Conde, sin embargo, no conocemos ni las condiciones estipuladas en él, ni cuánto recibían las encomenderas por la cesión de derecho (cesión prohibida por las Leyes de Indias, a menos de obtener una concesión especial de la Corona). ${ }^{5}$ El 10 de julio de 1708 se celebra un nuevo contrato entre las monjas, los herederos del Conde y el nuevo arrendatario, Don Cristóbal de Es. querra de Rosas, secretario del rey, por el cual se cedía a éste lo que

3 Zavala, 1973: 208.

4 AGDCA, A3.2 leg. 25 exp. 467.

5 Zavala, 1973: 211. 
había producido la encomienda por un periodo de tres años a partir del 17 de octubre de 1704 hasta el 16 de octubre de 1707; un total de 1638 pesos, 5 reales y 33 maravedís, libres de todo descuento, ${ }^{6}$ según certificación de Don Antonio de Herrarte, contador de la Audiencia.

Debido a que los usufructuarios no habían satisfecho el pago de una serie de deudas para con la Real Hacienda, la encomienda fue em. bargada, y los tributos que le correspondían se empezaron a cobrar por los oficiales reales desde los tiempos de Don Joseph Damián y Córdova, alcalde mayor de Chiapas. No obstante, por real cédula de 11 de abril de 1726 quedó exonerada Sor Feliciana del pago del derecho de lanzas y del descuento del diez por ciento, gracias a lo cual la encomienda quedó libre del embargo, presentándose el capitán Don Mi. guel Eustachio de Uría, podatario de Sor Águeda y Sor Feliciana ante la Real Audiencia a reclamar el pago de lo caído. La cédula se asentó en los libros el 21 de mayo de $1727 .{ }^{7}$

La muerte de Sor Águeda del Padre Eterno debió de haber acon. tecido entre 1721, en que figura como otorgante del poder al capitán Uría para solucionar los problemas de la encomienda ante la Audien. cia de Guatemala, y el año de 1726, en que el rey exonera a Sor Feliciana de diversos adeudos que tenía la encomienda. En este docu. mento no se menciona ya a Sor Águeda. A partir de la muerte de su madre, Sor Feliciana permaneció como única encomendera hasta el 14 de marzo de 1757 , fecha en que falleció. ${ }^{8}$

Muchos años después, en 1791, Don Bernardo Cassin, mayordomo del convento de La Baronesa, se presentó ante el Santo Oficio en representación de la priora Teresa de la Concepción, y solicitó que se tramitase la entrega de cierta cantidad de dinero que quedó depositada en la Caja Real de Guatemala, producto de la encomienda que había poseído Sor Feliciana y que no se le había entregado en vida. El rey ordenó que se realizase una investigación en la Audiencia y se hiciera efectivo al convento todo lo que se encontrase perteneciente a dicha encomienda, pero debido al largo tiempo transcurrido, lo único que se pudo averiguar fue que en el año de 1766, siendo alcalde mayor de Chiapas Don Joaquín Prieto Isla, se remitieron a la Caja de Guatemala 1798 pesos 5 reales que existían en la Caja de Chiapas, provenientes del remate de los tributos de la encomienda de Sor Feliciana y que nadie había reclamado.

Algunos años después, al dictarse la ley que señalaba que toda la

${ }^{6}$ AGDGA, A3.16 leg. 293 exp. 3949.

7 AGDGA, A1.23 leg. 2164 exp. 32463.

8 AGDCA, A1.23 leg. 4606 fol. 233. 
moneda en curso debería de fundirse para hacer la nueva que llevaba la efigie de Carlos III, hubo una merma, por lo que en 1799, año en que termina el expediente, sólo quedaba para entregar al convento la cantidad de 1695 pesos $11 / 2$ reales. Es en esta última fecha cuando parece concluir la información relativa a esta singular encomienda, siendo de notar que hacía ya muchos años que se habían extinguido las que existieron en la región.?

\section{Los tributarios}

Resulta difícil precisar cuál fue el comportamiento de la población encomendada ya que los datos se encuentran muy dispersos, requiriéndose de un trabajo profundo sobre este problema a nivel regional, pues es hasta fines del siglo xvm cuando se efectúan las primeras estadísticas sobre la población de Chiapas.

Sin embargo, el número de tributarios que tenían los pueblos de la encomienda se puede calcular indirectamente a través de la cantidad de dinero que era pagado por el servicio de la doctrina, pues sabemos que estaba estipulado el que cada 400 tributarios pagaran a razón de 50000 maravedís. La doctrina pagada en 1706 fue de 193 pesos 7 reales, lo cual equivale a 52734 maravedís, de donde podemos deducir que el número de tributarios era de 422 para principios del siglo xviII. No conocemos cuál fue el número de tributarios en cada uno de los pueblos, pero por la cantidad de tributo recolectado se puede deducir que Tapizala y Soyatitlán eran los de mayor importancia. ${ }^{10}$

\section{Los tributos}

El tributo de un pueblo se fijaba de acuerdo con su población y era en los productos de la región. Del total que se recolectaba, tomaban lo que les correspondía: el encomendero, la Iglesia y la Corona, de acuerdo a lo fijado en las tasaciones vigentes. El tributo se entregaba en dos periodos: por el día de San Juan (24 de junio) y en Navidad.

En la tasación del pueblo de Pantepeque vigente para el año de 1712 se puede observar cómo se distribuía el total de los tributos. ${ }^{11}$

9 AGDCA, A3.2 leg. 25 exp. 467.

10 AGDCA, A3.16 leg. 293 exp. 3949.

11 AGDCA, A3.16 leg. 299 exp. 4043; cada zontle equivale a 400 unidades; el xiquipil contiene 20 zontles y una carga de cacao tiene 60 zontles; una manta zoque tiene 3 piernas y cada pierna tiene de dimensión 3 varas de largo por $2 / 3$ de vara de ancho. 


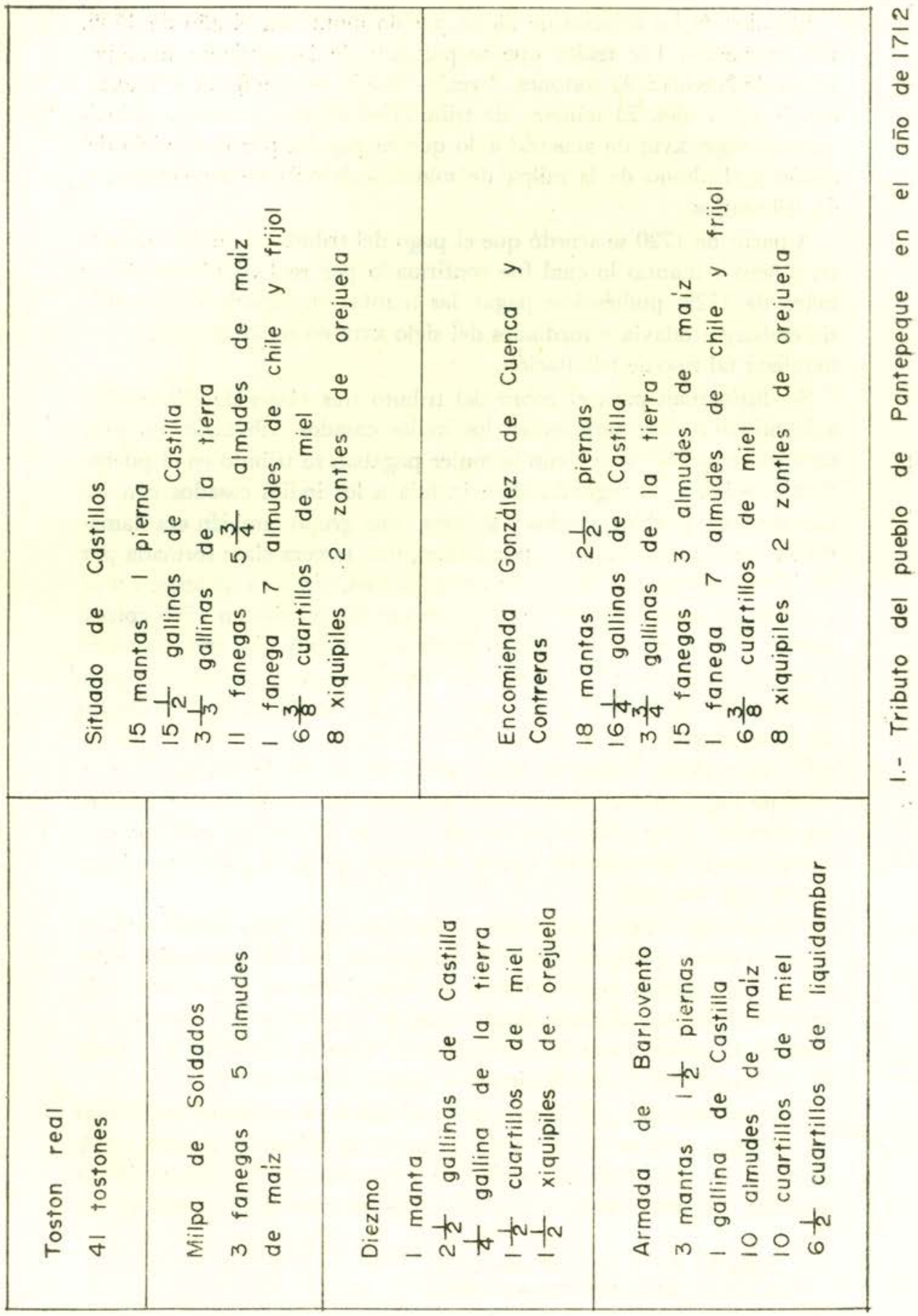

Estudios de Cultura Maya. Vol. XIII, 1981

Instituto de Investigaciones Filológicas/

Centro de Estudios Mayas, UNAM

http://www.iifilologicas.unam.mx/estculmaya/ 
El valor de los tributos de dicho pueblo montó en el año de 1755, 194 tostones $61 / 2$ reales que se pagaron de la siguiente manera: tercio de Navidad 93 tostones, 3 reales; tercio de San Juan 101 tostones, $31 / 2$ reales. El número de tributarios de Pantepeque a principios del siglo xviII de acuerdo a lo que se pagaba por el servicio del tostón y el almud de la milpa de soldados debería de ser cercano a 41 tributarios.

A partir de 1720 se acordó que el pago del tributo fuese únicamente en dinero y mantas lo cual fue confirmado por real cédula de 31 de mayo de 1722, pudiéndose pagar las mantas en especie o dinero; ${ }^{12}$ sin embargo todavía a mediados del siglo xvir no se había logrado generalizar tal tipo de tributación.

Se distinguían para el cobro del tributo tres clases de tributarios; a la primera clase pertenecían los indios casados tributarios enteros, donde tanto el hombre como la mujer pagaban su tributo en el pueblo donde residían; la segunda clase incluía a los indios casados con in. dias de otros pueblos, viudos y solteros (este grupo también era llamado de medios tributarios) y por último, una tercera clase formada por las indias casadas con indios de otros pueblos, viudas y solteras. En la tasación de la parcialidad de Tutuapa llevada a cabo en 1706 corres. pondió a cada una de las clases pagar lo siguiente: los tributarios de primera clase debían de pagar una manta de a tres piernas zoques, ocho zontles de cacao y una fanega de maíz; los tributarios de segunda clase pagaban una y media pierna de manta zoque, cuatro zontles de cacao y media fanega de maíz, mientras que los de tercera clase solamente pagaban una pierna de manta, dos zontles de maíz y doscientos sesenta y siete granos de cacao. ${ }^{13} \mathrm{El}$ caso de pueblos como Pantepeque donde se tributaba mayor variedad de productos, era obviamente más complejo.

Además del tributo, los indios tenían que dar cierta cantidad para la comunidad, que generalmente era pagada por los tributarios enteros, y que algunas veces consistía en una pierna de manta por cada uno de ellos, más algunos petates que se pagaban entre toda la población. El producto de la venta de estos tributos ingresaba a la Caja de la Comunidad y era destinado a gastos comunales.

Las personas que por alguna enfermedad se encontraban impedidas de trabajar, y los ancianos, estaban exentos de tributo. Por otra parte, al hacer la cuenta de un pueblo se rebajaban de la numeración a aquellas personas que ocupasen los cargos de alcalde del pueblo y sa-

12 AGDCA, A3.16 leg. 295 exp. 3974.

13 AGDCA, A3.16 leg. 358 exp. 4611. 
cristán de la iglesia; en las poblaciones mayores se incluían en la exención los ocupantes de cargos tales como los de maestro cantor, maestro de coro y otros más.

A continuación se dan las cuentas de la encomienda de Sor Águeda y Sor Feliciana para el año de 1706 que aparecen certificadas por Don Antonio Herrarte, contador de la Audiencia.

Cargos: $\mathrm{El}$ año de mil setecientos y seis le tocaron a dicha encomienda en los pueblos de Tapizala, parcialidad nombrada Amatlán, Pantepeque, Chapultenango, Istacomitlán y San Andrés Nicapa, doscientas y cuarenta y nueve mantas de a tres piernas y tres octavos de una pierna zoques, libres de diezmo que a veinte y un reales cada manta, que es el precio del remate, importan seiscientos cin. cuenta y tres pesos siete reales y veinte y dos maravedís.

Así mismo le tocaron en dicho año de mil setecientos y seis a dicha encomienda en el pueblo de Soyatitlán, ciento y treinta y ocho mantas y una pierna de a tres piernas zendales, libres de diezmo, que a trece reales de su remate montan doscientos siete pesos cuatro reales y once maravedís.

Así mismo montaron dicho año de mil setecientos y seis las legumbres y cacao que le tocaron, en los siete pueblos expresados a los remates, libres de diezmo, trescientos noventa y siete pesos seis reales y nueve maravedís.

Por manera que las tres partidas referidas que así le tocaron a dicha encomienda el año expresado de mil setecientos y seis, suman y montan mil doscientos cincuenta y nueve pesos dos reales y ocho maravedís según consta y parece de dichas partidas. De los cuales se deben rebajar las cargas que paga cada año dicha encomienda que son las que se siguen:

Primeramente se rebajan ciento y ochenta y dos pesos y cuatro reales por la escudería o lanza que llaman, que se paga en la Real Caja de esta Corte para el situado de Castillos. ${ }^{14}$

Así mismo se rebajan veinte y seis pesos y cinco reales que se pagan en la Real Aduana de esta Corte por la razón de Alcabalas y Barlovento.

Así mismo se rebajan cien pesos cinco reales y diez y seis maravedís que le tocan al dicho Sargento Don Domingo Ayarza por razón del premio de la administración, a razón de ocho por ciento de los mil doscientos cincuenta y nueve pesos dos reales y ocho maravedís.

Así mismo se rebajan ciento y noventa y tres pesos y siete reales por las doctrinas de los pueblos referidos que se pagan a los curas doctrineros de ellos a razón de 50000 maravedís por cada cuatro-

14 El encomendero estaba obligado a ayudar a la defensa de la tierra, por lo que se veía forzado a tener caballo, lanza y otras armas defensivas de acuerdo al valor de los tributos de su encomienda; en caso de residir fuera de la provincia se designaba un escudero que cumplía estas funciones y el cual era pagado por el encomendero. Es éste el origen de la carga de escudería o lanza en el estado de cuentas de la encomienda. 
cientos tributarios por la doctrina y administración de los Santos Sacramentos. ${ }^{15}$

Así mismo se rebajan ciento y diez y siete pesos cuatro reales y veinte y cinco maravedís por el vino y aceite de las religiones que cada año se paga.

Así mismo se rebajan quince pesos por el flete de las mantas y cacao desde los pueblos a Ciudad Real de Chiapa, que se paga a los naturales de dichos pueblos.

Así mismo se rebajan cuarenta y dos pesos por el flete de las mantas, petacas y petates desde Ciudad Real de Chiapa hasta esta ciudad que dista ciento doce leguas.

Por manera que las siete partidas referidas de las cargas que así se deben rebajar de los mil doscientos cincuenta y nueve pesos dos reales y ocho maravedís que importan los tributos, suman y montan seiscientos setenta y ocho pesos dos reales y siete maravedís.

De modo que comparados los mil doscientos cincuenta y nueve pesos dos reales y ocho maravedís que importaron los tributos del año referido de mil setecientos y seis con los seiscientos setenta y ocho pesos dos reales y siete maravedís que se pagaron de cargos restan en que le quedaron útiles y libres de todos cargos en dicho año de mil setecientos y seis a dicha encomienda, quinientos ochenta y un pesos y un maravedí según consta y parece de esta cuenta a que me refiero. ${ }^{16}$

A continuación se anotan los datos de los tributos que cada uno de los pueblos daba a la encomienda, ${ }^{17}$ y los precios en los que se remataban. ${ }^{18}$

$15 \mathrm{La}$ justificación teórica de la encomienda se basaba en que era necesaria para el bien espiritual y temporal de los indios y por consiguiente era preciso acudirlos con las enseñanzas de la fe católica.

16 AGDCA, A3.16 leg. 293 exp. 3949.

17 Ibid.

18 AGDCA, A3.16 leg. 2803 exp. 40524 y A3.16 leg. 293 exp. 3949. 


\begin{tabular}{|c|c|c|c|c|c|c|c|}
\hline OHDíd & & & & & & $-k$ & \\
\hline odaulp & & & & 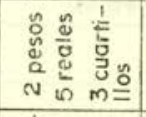 & & & \\
\hline pquppinb!r & & & & 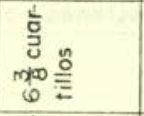 & & & \\
\hline $1 a ! w$ & & 145: & & 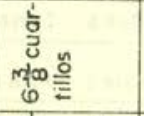 & & & \\
\hline DIaniajo & & 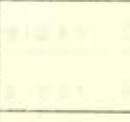 & & 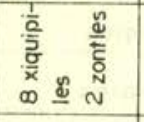 & & & \\
\hline $\begin{array}{l}\text { Dमयग! } \\
\text { DI } \partial P \\
\text { SDU!IIDG }\end{array}$ & & & $n$ & $m_{m}$ & $\underset{m}{m}$ & & \\
\hline $\begin{array}{l}\text { DII!SDO } \\
\text { วP } \\
\text { SDU!IIDE }\end{array}$ & $\stackrel{0}{0}$ & $\frac{n}{4}$ & $\begin{array}{l}-1 N \\
a \\
-\end{array}$ & $\begin{array}{c}-10 \\
\underline{6}\end{array}$ & $\begin{array}{l}-1 N \\
\underline{\omega}\end{array}$ & & $\begin{array}{l}-1 N \\
n \\
m\end{array}$ \\
\hline $\begin{array}{l}\text { 10!1य! } \\
\kappa \quad \text { श!!पว }\end{array}$ & 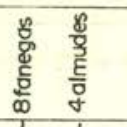 & 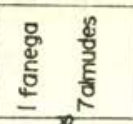 & 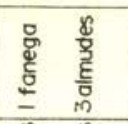 & 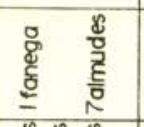 & 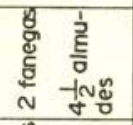 & & 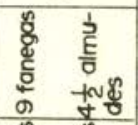 \\
\hline ziow & 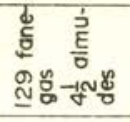 & है & 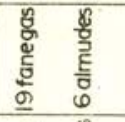 & 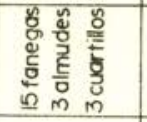 & 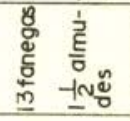 & 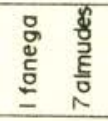 & $\begin{array}{ll}8 & \wp \\
8 & 8 \\
\frac{8}{8} & \text { है } \\
\stackrel{0}{0} & 0\end{array}$ \\
\hline 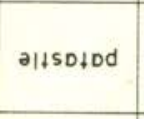 & & & 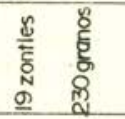 & & & & \\
\hline$O D \supset 0 O$ & & 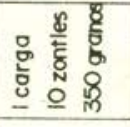 & w & & 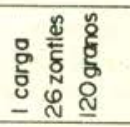 & 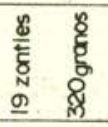 & \\
\hline $\begin{array}{l}\text { Sa|Opuaz } \\
\text { SofuDW }\end{array}$ & & & & & & & 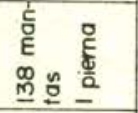 \\
\hline \multirow[t]{2}{*}{$\begin{array}{l}\text { sanboz } \\
\text { sotuou }\end{array}$} & 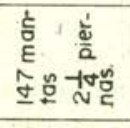 & 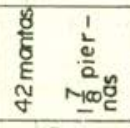 & 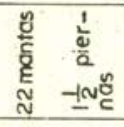 & 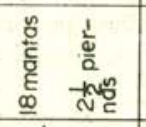 & 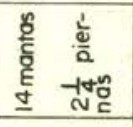 & 号 & \\
\hline & $\begin{array}{l}\text { 음 } \\
\text { 흠 }\end{array}$ & 兽 & 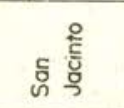 & 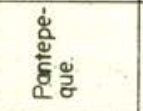 & $\frac{\circ}{\mathrm{O}}$ & 음 & 容든 \\
\hline
\end{tabular}




\begin{tabular}{|c|c|c|}
\hline & 1625 & 1706 \\
\hline mantas zoques & 18 reales & 21 reales \\
\hline mantas zendales & & reales \\
\hline $\operatorname{cacao}$ & 40 tostones carga & 24 tostones carga \\
\hline patastle $(19)$ & & I real zontle \\
\hline maiz & 6 reales fanega & 6 reales fanega \\
\hline chile y frijol & 8 reales fanega & 12 reales fanega \\
\hline gallinas de Castilla & 2 reales & 2 reales \\
\hline gallinas de la tierra & 4 reales & 4 reales \\
\hline Orejuelo $(20)$ & & 4 reales xiquipil \\
\hline miel & & I real cuartillo \\
\hline liquidambar (21) & & I real cuartillo \\
\hline petate & & 2 reales \\
\hline
\end{tabular}

3.- Valor de los tributos de la encomienda

19 El patastle, Teobroma bicolor; es una especie de cacao considerada de baja calidad con escaso valor comercial de acuerdo a Faustino Miranda (1952). En la visita que hizo Don Miguel del Pino, alcalde mayor de Tuxtla a la región a finales del siglo xvin anotó en su diario que al patastle lo pudren y queda por dentro como almidón, que solamente se consumía en Oaxaca y sus aledaños y era utilizado para hacer espuma a ciertas bebidas, Archivo Histórico del Estado, 1953.

20 Orejuela, Cymbopetalum penduliflorum Baill; los pétalos secos de las flores son aromáticas y se usan como remedio casero para combatir el asma y como tónico estomacal, también recibe el nombre de suchinacaste según Faustino Miranda (1952), en tiempos prehispánicos y en la colonia fueron muy empleados para aromatizar el chocolate, y en las listas de tributos de la colonia se emplean indistintamente los nombres de orejuela o suchinacaste.

21 Liquidámbar, Liquidambar styraciflua; es una resina que se obtiene de cavidades del tronco y se usa en medicina como estimulante de la expectoración; en perfumería es empleado para la preparación de jabones y cosméticos; en los mercados de Chiapas, se vende un bálsamo de color negruzco, el cual se extrae por medio del calor, se usa como incienso en templos y casas, Miranda, (1952). [Sobre la extracción del liquidámbar y sus propiedades véase la curiosísima descripción dada por Ordóñez y Aguiar, en Bol. Arch. Gral. del Edo. Chiapas, No. 2, pp. 91 y ss., México, 1953. N. del E.] 


\section{La Real Hacienda y la encomienda}

Uno de los primeros descuentos fuertes que se le aplicaron a las encomiendas en el siglo xvir fue el quinto, del cual se servía la Corona para el sostenimiento de la Armada de Barlovento, en cumplimiento de una real cédula librada en Madrid con fecha del 16 de junio de 1649. El quinto se descontaba del valor de los tributos recolectados, y en aquellas encomiendas con varios pueblos tributarios, el valor del quinto se cargaba a un solo pueblo para facilitar la recolección. ${ }^{22}$ Hasta el año de 1678 todavía se encuentran documentos donde aparece el cobro de esta carga extraordinaria. ${ }^{23}$

En el reinado de Carlos II los descuentos se hicieron más frecuentes y así, en una cédula del 2 de septiembre de 1687, se ordenaba el desfalco de la media anata de todas las encomiendas, deducidas primero las cargas normales, empezando a tener efecto desde el primero de enero de 1688 y con una duración de cuatro años. En 1691 se dicta otra cédula que prorroga este descuento hasta el primero de enero de 1695,24 y otra vez el 11 de febrero de 1697 se vuelve a recurrir a la aplicación de este descuento por un periodo que abarca desde el pri. mero de enero de 1697 hasta fines de 1701 .

En general, tal descuento se hacía necesario, según la Corona, para que se pudiesen mantener las fuerzas marítimas que estaban en las Indias para la defensa de sus costas. Entre las encomiendas que estaban exceptuadas del pago de la media anata se encontraban aquéllas cuyo producto útil no pasaba de doscientos pesos anuales..$^{25}$

En el siglo xvirr con el cambio de la dinastía de los Austrias de Es. paña, y las guerras originadas por la sucesión del trono, se hizo todavía más crítica la situación financiera de la Corona, por lo que Felipe $\mathrm{V}$ se vio en la necesidad de volver a aplicar el descuento de la media anata, y así se comunica en una real cédula del 17 de abril de 1703 . Igual que en las disposiciones anteriores, se declaraba exentas encomiendas que no pasasen de doscientos pesos al año, libres de todo gasto; el descuento se debería de aplicar desde el día que se hiciese pública en las Indias la real cédula. ${ }^{26}$ Sabemos que en Guatemala su vigencia fue desde fines de junio de 1703 hasta 1705, tal como lo or-

22 Archivo General del Gobierno, 1936-37.

23 AGDCA, A3.16 leg. 290 exp. 3914.

24 Zavala, 1967: 89.

25 Muro Orejón, 1956. La media anata descontaba la mitad del producto útil de las encomiendas, para la Real Hacienda.

26 Ibid., 1969. 
denaba la cédula, y que Sor Águeda y Sor Feliciana estuvieron exentas de su pago, pues al arrendarle su encomienda a Don Cristóbal de Esquerra éste no sufrió el descuento:

Los 1638 pesos 5 reales y 33 maravedís expresados son por lo que han producido los frutos de la encomienda expresada en los tres años citados, libres de cargos sin descuento alguno de media anata conforme al dicho ajuste, sin embargo de haber sido comprendida desde el 16 de octubre de 1704 hasta fin de junio de 1705 , en virtud de real cédula de su majestad expedida en esta razón... ${ }^{27}$

Como mencionamos antes, la encomienda estuvo embargada por la Real Hacienda a principios del siglo xvmr, pero con el favor real Sor Feliciana logró su desembargo. ${ }^{28}$

\section{Conclusiones}

Para 1750 ya solamente quedaban en Chiapas tres encomiendas: la del convento de la Encarnación de Ciudad Real que recibía los tributos del pueblo de Tapalapa; la de Sor Josepha de Mencos sobre San Bartolomé de los Llanos y la de Sor Feliciana de San Antonio. El hecho que las tres estuvieran en posesión de religiosas nos indica que para el momento de su extinción en Chiapas, la encomienda era una merced que se había mantenido a ciertas personas habiendo perdido totalmente la función que tuvo al momento de implantarse. ${ }^{29}$

A lo largo de la historia de la encomienda, se puede apreciar cómo se van reduciendo los ingresos de ella derivados, pues en 1726 el rey (?) menciona que unos años antes sólo le quedaban útiles 374 pesos y que luego se redujeron a 200 pesos debido a la muerte de los tributarios y a otros problemas, ${ }^{30}$ todo esto, a pesar de que los documentos indican que las cargas extraordinarias que la Corona imponía a los encomenderos no se hicieron efectivas en el caso de esta encomienda, cargas que debieron de lesionar fuertemente los intereses de aquellas personas que no estuvieron lo suficientemente cerca del favor real para conseguir la exoneración.

En general la cercanía del encomendero al poder real, podía hacer que el curso particular de su encomienda se viera favorecido y así

\footnotetext{
27 AGDGA, A3.16 leg. 293 exp. 3949.

28 AGDCA, A1.23 leg. 2164 exp. 32463.

29 AGDCA, A3.16 leg. 295 exp. 3974.

30 AGDCA, A1.23 leg. 2164 exp. 32463.
} 
lograr las modificaciones necesarias a las leyes de la sucesión y a la política hacendaria de la Corona, como puede colegirse de los datos anteriores.

\section{BIBLIOGRAFIA}

Archivo General de Centro-América (AGDCA)
A3.2 leg. 25 exp. 467.
A3.16 leg. 290 exp. 3914.
A3.16 leg. 293 exp. 3949.
A3.76 leg. 295 exp. 3974.
A3.16 leg. 299 exp. 4043.
A3.16 leg. 358 exp. 4611 .
A1.23 leg. 2164 exp. 32463.
A3.16 leg. 2803 exp. 40524.
A1.23 leg. 4606 fol. 233.

Archivo General deL Gobierno

1936-37 "Título de encomienda a varios descendientes de conquistadores y pobladores antiguos del reyno de Guatemala". Boletín del Archivo General del Gobierno, Vol. II, pp. 3-19. Guatemala.

ARchivo Histórico del Estado

1953 "Diario de viaje del alcalde mayor de Tuxtla, 1783-1789". Documentos Históricos de Chiapas, Boletín del Archivo Histórico del Estado, Vol. II, pp. 66-89. Tuxtla Gutiérrez, Chiapas.

Miranda, Faustino

1952 La Vegetación de Chiapas. Gobierno del Estado. Tuxtla Gutiérrez, Chiapas.

Muro Orejón, Antonio (ed.)

1956-69 Cedulario Americano del Siglo xvın. Escuela de Estudios Hispano-Americanos de Sevilla. Sevilla.

Zavala, Silvio A.

1967 Contribución a la Historia de las Instituciones Coloniales en Guatemala. Editorial Universitaria. Guatemala.

1973 La Encomienda Indiana. Ed. Porrúa. México. 